\title{
Vascular Ring
}

National Cancer Institute

\section{Source}

National Cancer Institute. Vascular Ring. NCI Thesaurus. Code C99106.

An unusual congenital abnormality in which the aorta or aortic branches encircle the trachea and esophagus. Signs and symptoms include difficulty swallowing and eating, persistent cough, noisy breathing, and acid reflex. 